\title{
Correspondence: a further case of opsoclonus-myoclonus syndrome associated with Mycoplasma pneumoniae infection
}

\author{
Takashi Shiihara $\cdot$ Yukitoshi Takahashi
}

Received: 2 October 2009 /Revised: 17 October 2009/Accepted: 6 November 2009/Published online: 27 November 2009

(C) Springer-Verlag 2009

Sir:

Huber et al. have reported the cases of three adolescents with opsoclonus-myoclonus syndrome (OMS) after Mycoplasma pneumoniae infection [2]. We report another such patient with OMS, who showed autoantibodies against glutamate receptors (GluR).

A 12-year-old girl, otherwise healthy except for bronchial asthma, presented with a 5-day history of jerky movements of her extremities and eyes and inability to walk. One week earlier, she had suffered from a respiratory disease, and at that time, the particle agglutination test for M. pneumoniae antibody was strongly positive ( $>1: 10,240$; titers of $\geq 1: 40$ are regarded positive). Thorough examinations such as hematology, blood chemistry, electroencephalography, brain imaging, and cerebrospinal fluid (CSF)

T. Shiihara $(\bowtie)$

Department of Neurology, Gunma Children's Medical Center,

779 Shimohakoda Hokkitsu-machi,

Shibukawa, Gunma 377-8577, Japan

e-mail: shiihara-ind@umin.net

\section{T. Shiihara}

Department of Pediatrics, Koshigaya Hospital,

Dokkyo Medical University,

2-1-50 Minami-Koshigaya,

Koshigaya, Saitama 343-8555, Japan

Y. Takahashi

National Epilepsy Center,

Shizuoka Institute of Epilepsy and Neurological Disorders, 886 Urushiyama,

Shizuoka 420-8688, Japan examination revealed normal findings; no signs of neuroblastoma were observed.

Initially, the symptoms of OMS gradually improved. However, these symptoms worsened on day 28; therefore, intravenous immunoglobulin (IVIG) was administered at $2.0 \mathrm{~g} / \mathrm{kg}$. The symptoms of OMS began to improve within several days; however, they worsened around day 50. Therefore, IVIG was added at $1.0 \mathrm{~g} / \mathrm{kg}$, and intravenous methylprednisolone pulse therapy $(30 \mathrm{mg} / \mathrm{kg} / \mathrm{day}$ for three consecutive days) was administered three times at intervals of 1 week. The symptoms of OMS gradually disappeared by day 150 with no apparent sequelae.

GluR $\delta 2$ is predominantly expressed in cerebellar Purkinje cells; it plays a crucial role in cerebellar functions and is reportedly associated with cerebellitis [3]. On day 30 , the serum was positive, but CSF was negative for anti-GluR IgG- $\delta 2$ and IgM- $\delta 2$ antibodies. These findings indicate that the etiological role of these antibodies is uncertain; however, they may be a surrogate marker of autoimmunity. Autoimmunity may play a role in OMS. Further studies are required to detect specific autoantibodies in cases of M. pneumoniae-related OMS [1].

Conflict of interest There was no conflict of interest.

\section{References}

1. Blaes F, Pike MG, Lang B (2008) Autoantibodies in childhood opsoclonus-myoclonus syndrome. J Neuroimmunol 201-202:221-226

2. Huber BM, Strozzi S, Steinlin M et al (2009) Mycoplasma pneumoniae associated opsoclonus-myoclonus syndrome in three cases. Eur J Pediatr. doi:10.1007/s00431-009-1048-3

3. Shiihara T, Kato M, Konno A et al (2007) Acute cerebellar ataxia and consecutive cerebellitis produced by glutamate receptor delta2 autoantibody. Brain Dev 29:254-256 